\title{
LESBIAN, GAY, BISEXUAL, TRANSGENDER AND INTERSEX (LGBTI) STUDENTS ARE SCRAMBLING FOR ACCESS TO HEALTHCARE SERVICES IN THE CAMPUS HEALTHCARE SYSTEM: PERCEPTIONS OF KEY INFORMANTS
}

\author{
A. V. Kleinhans \\ Public Health \\ Sefako Makgatho Health Sciences University \\ Pretoria, South Africa \\ e-mail: atholl.kleinhans@smu.ac.za
}

\section{ABSTRACT}

This article explores the experiences of lesbian, gay, bisexual, transgender and intersex (LGBTI) students and focuses specifically on how they access healthcare in the campus health system at a university in South Africa. Semi-structured, in-depth key informant interviews were conducted with selected representatives from all service providers in the campus healthcare system including a gender expert and a student leader. The findings of this study show that LGBTI students are underserved in the campus healthcare system and this is the result of a heteronormative campus environment. The implications of this study suggest the critical need for support from university management, student mobilisation, and sensitisation training for healthcare providers.

Keywords: heteronormativity, access to healthcare, LGBTI, higher education, South Africa.

\section{INTRODUCTION}

University campuses in South Africa and elsewhere are a "home away from home" (Arndt and De Bruin 2006) where many students with diverse social and cultural backgrounds meet on a daily basis. Higher Education Institutions (HEIs) often present with a multitude of diversities and this makes it possible for some students who identify as LGBTI to find space and freedom to "claim" and negotiate their same-sex identities when they reach university (Arndt and De Bruin 2006; Francis and Msibi 2011; Soudien 2008). However, this is not the same for all LGBTI students nor does it mean that they are accepted in these spaces. In fact, Msibi (2013) noted that while students in South Africa often perceive universities as diverse and liberal environments, the opposite often happens. Experiences of homophobia, biphobia and transphobia become a daily occurrence for many students with non-normative gender expressions and sexual identities, and literature highlights a lack of access to culturallycompetent healthcare service providers for these students (Mavhandu-Mudzusi 2016).

Historically, LGBTI individuals in South Africa, experienced discrimination on the basis 
of their sexual orientation and gender identity and generally were excluded from social life (Arndt and De Bruin 2006; Matthyse 2017). Consequently, research conducted at universities to normalise sexual orientation and gender identity would have been extremely difficult because homosexuality was a criminal offence under the apartheid regime. Universities in South Africa, during the apartheid years, found themselves in a precarious position. Nduna et al. (2017) argue that some of these institutions served the apartheid government, which meant that their financial stability was totally dependent on their collegial relationship with the government. Academic freedom, on the other hand, was non-existent in certain HEIs, simply because they had a duty to preserve the apartheid status quo and this strongly influenced the academic agenda for these institutions (Bunting 2006). These power systems do not simply disappear when there is regime change; rather they have a lasting impact. The South African narrative on homosexuality, which accentuates the dualism between constitutional protections of sexual minorities (Francis 2017a; $2017 \mathrm{~b}$ ) and the "actual experiences of acceptance (at best) and homophobia (at worst) in civil society" (Rothmann 2018), bears evidence of this.

This stark contrast between the constitutional provisions for the equal rights of LGBTI persons and the actual negative experiences of stigma, discrimination and violence has also been observed in the higher education sector in South Africa (Brink 2017). This, according to Matthyse (2017), is fuelled by a system that normalises heterosexuality and is strongly supported by an ever-present patriarchal system. Francis $(2017 \mathrm{a} ; 2018)$ refer to this as "compulsory heterosexuality" where the presence of those students who present with nonnormative gender expressions and sexual diversities are flatly denied therefore rendering them invisible in these spaces. A conceptual understanding of how these power (oppressive) systems operate at the institutional level is necessary in order to address these structural barriers.

A blending or mixture of organisational culture and the disciplinary institution, as defined by Foucault (1995), constitutes institutional culture (Swindler, 1986). In recent times, we have witnessed the emergence of the "Rhodes must fall" campaign at the University of Cape Town, which marked the beginning of the largest wave of student protest under the new democratic government and ultimately lead to the "Fees must fall" campaign. These are clear attempts by students to address the dominant oppressive colonial systems ever-present in our higher education environment, where students argued that current symbols such as many statues on campuses around the country are remnants of our not-so-distant colonial past. It was also through these very colonial penal codes that homosexuality was also declared illegal and a crime.

Transformation in terms of sexual orientation and gender identity in the higher education sector post-apartheid was slow and it was only about two decades later that reforms pertaining 
to gender policies and practices started to emerge (Badat 2009). One example is the establishment of the Higher Education and Training Health, Wellness and Development Centre (HEAIDS) in 2000/2001 as a partnership between the then Department of Education, the South African Universities Vice-Chancellors Association and the Committee of Technikon Principals. The programme was initiated as part of the sectors response to the HIV/AIDS epidemic. Subsequently the programme expanded to include aspects of sexual orientation and gender identity. In 2014, it commissioned the first National Student Sexual Health HIV Knowledge, Attitude and Behaviour Survey, which focused exclusively on student men who have sex with men at 14 HEIs in South Africa (Brink 2017). The study did not focus on the health status of students.

Adolescence ranges from 12 to 24 years of age and is usually associated with sexual and identity development (World Health Organization (WHO) 2011). University students fall within this age group and literature from South Africa highlights healthcare disparities among sexual minority students (Müller 2017; Mavhandu-Mudzusi 2016). Adolescents who identify as LGBTI are at higher risk of poor physical and mental health compared to their heterosexual counterparts (Strutz, Herring and Halpern 2015). For example, Haas et al. (2010) reported that the likelihood of death by suicide for sexual minority youth is estimated to be two to seven times greater than the likelihood of death by suicide among heterosexual youth. More importantly, over and above the individual-level risk factors, the social environment appears to contribute to risk for suicide attempts (Hatzenbuehler 2011).

Access to healthcare is a critical factor in how we assess the performance of healthcare systems around the world (Mavhandu-Mudzusi 2016; Müller 2017). While a clear, universallyaccepted definition for access to healthcare is absent in literature, "the timely use of service according to need" (Peters et al. 2008, 162) is used in this study. There are four dimensions of access: availability, accessibility, affordability and acceptability (Jacobs et al. 2012). Some researchers suggest that barriers to accessing healthcare can stem from demand-side and/or supply-side factors (Ensor and Cooper 2004; O'Donnell 2007). The factors that affect the ability to use health services at individual, household or community level are referred to as demand-side determinants and those factors inherent to the healthcare system that hinder service uptake by individuals, households or the community are called the supply-side determinants (Jacobs et al. 2012).

The differences in the healthcare LGBTI individuals receive as opposed to their heterosexual counterparts has been linked to societal stigma, discrimination, and denial of their civil and human rights and severely restricts their access to healthcare (Nduna et al. 2017). LGBTI youth are particularly vulnerable and, according to the Institute of Medicine (IOM) 
(2011) in the United States, they show a worse health profile than both adolescents and adults in their late twenties and thirties although most of the health problems reported are preventable, meaning that there are opportunities to intervene and promote lifelong health among this group. LGBTI health requires specific attention from the healthcare system and public health professionals need to address a number of health disparities including but not limited to the likelihood of engaging in high-risk sexual behaviours leading to an increased incidence of sexually transmitted infections and HIV (Brink 2017), and a greater incidence of mental health issues such as depression, anxiety, and increased suicidal behaviours than heterosexual adolescents.

Little is known about the experiences of LGBTI students is accessing healthcare in the higher education sector in South Africa. Available research has looked at the broader experiences of LGBTI students within universities but not how they experience healthcare. Mavhandu-Mudzusi (2016) reported healthcare disparities among LGBTI students at a rural university where she conducted her study. For example, participants in her study reported that the healthcare services at the university discriminated against LGBTI students because they only focused on heterosexual students. Therefore, this study explored the experiences of LGBTI students accessing healthcare in the campus healthcare system.

\section{METHODS}

An exploration of the experiences of LGBTI students and a description of how they access healthcare in the campus health system was the aim of this study. The campus healthcare system is comprised of but not limited to the campus clinic, the HIV office and psychological services. This qualitative enquiry was conducted over a 10-month period during February and November of 2016 .

The characteristics of an entire population cannot be studied through qualitative research methods; however, qualitative methods do allow for a more detailed account of individuals' experiences as members of LGBTI communities (IOM 2011) and as Binson et al. (2007) assert, they offer unique opportunities to understand LGBTI health.

The study used five key informant interviews and one focus group discussion to answer the research questions. This article only reports on the key informant interviews. Semistructured interviews were conducted with five key informants in order to explore the experiences of LGBTI students. Key informant interviews are most appropriate where little is already known about the study phenomenon or where detailed insights are required from individual participants. The key informants were also instrumental in recruiting study participants for the focus group discussion, due to the sensitive nature of the study topic. The 
key informants were purposively selected based on their expert knowledge about the topic under study and/or their direct involvement with students through the rendering of healthrelated services to students. Three of the interviewees were selected from the campus healthcare system in order to gain a better understanding regarding the experience of LGBTI students accessing healthcare and to provide a healthcare-provider perspective. Two additional interviewees were selected in order to provide both a professional gender perspective as well as the voice of the sexual minority student leadership.

The data collection procedure for this study was inspired by Creswell's (2014) model of data collection. During the time of the study, the researcher was employed by the university where the research was conducted, and this informed the selection of the study site. Ethical clearance with clearance number HSHDC/525/2016 was obtained from the UNISA ethics committee prior to the commencement of the study. All other permissions from university authorities were also sought prior to conducting this study. Qualitative research in general and qualitative data analysis specifically is certainly not linear but rather iterative and goes back and forth (Ritchie, Spencer and O'Connor 2003) until the researcher has reached data saturation. This was well illustrated in this study. The researcher went back to the participants and conducted what Creswell (2014) and Creswell and Miller $(2000,127)$ refer to as "member checking" to verify the data as soon as data analysis was completed.

One of the challenging tasks for qualitative researchers is analysing text data and this is further exacerbated by decisions on how to represent the data in tables, matrices and in narrative forms (Creswell 2007). Earlier it was mentioned that the qualitative research process is not linear such as quantitative research in which the investigator collects the data, then analyses the information, and finally writes the report (Creswell 2014). The qualitative research analysis process is iterative and occurs simultaneously with the data collection and interpretation processes. Data from the interviews and focus group discussions were digitally recorded and transcribed verbatim into a word document.

Thematic analysis, one of the most common forms of analysis in qualitative research, was used to analyse the data. This form of analysis was chosen because it emphasises, pinpoints, examines, and records patterns (or "themes") within data. Data were reduced into meaningful units and were coded and classified according to predefined categories, subcategories, and overall themes and the researcher adhered to the suggested number of between five to seven themes, as proposed by Creswell (2014). The categories were grouped into themes, which were directed by the research objectives. Axial coding was then applied to make connections between categories and codes. Data were analysed for manifest and latent content. Findings were contrasted in relation to data obtained from the key informant interviews and data in the 
literature. Thick descriptions and direct quotes were generated to contextualize the findings and to present the data.

\section{FINDINGS}

This study contributes to current knowledge about the institutional and structural barriers to accessing healthcare that are experienced by LGBTI students in the higher education sector. The findings show that these students experience various forms of structural and systemic barriers in the process of accessing healthcare services on campus and this is influencing their ability to use these services. All key informant interviews started with the same question: "Kindly tell me what is your understanding regarding LGBTI issues on campus and specifically in the healthcare system?" Two themes, namely, "Institutional factors", and "Healthcare system related factors" were generated from the analysis.

\section{Structural and systemic barriers to accessing healthcare}

The structural barriers to accessing healthcare are institutional (political and cultural in nature), and factors that are inherent to the healthcare system, and, collectively, these influences how LGBTI students experience access to healthcare services on campus.

\section{Institutional factors}

HEIs just like any organisation need effective leadership in order to achieve overall success (Jooste, Frantz and Waggie 2018) and this is crucial for policy makers, leaders themselves and for university staff. Institutional and structural barriers have the effect of fostering and maintaining systems of oppression in the campus environments according to most key informants, and they report that these create healthcare disparities among LGBTI students on campus. The institutional culture, which includes things such as the current artefacts, policies, practices and campus climate, has been influenced by a heteronormative system that creates discrepancies in how LGBTI students experience access to healthcare. Key informants perceived this as governance issues that restricts the availability of LGBTI specific services. Some key informants felt that the university management is not prudent when it comes to issues of sexual orientation and gender identity and this creates access barriers for sexual minority students.

Inclusive and non-discrimination policies in HEIs have been shown to be instrumental in ensuring the creation of an open and supportive campus atmosphere (Messinger 2002). Most key informants supported this idea but felt that management falls short of asserting their position and they feel that this is impacting the healthcare experience of LGBTI students. KI 1 
explained:

"I will start from top. I think the first thing is issues relating to governance ... policy-wise, if there is no clear strategy then what is the aim of a making sure that there is diversity and all of us adhere to that strategy for diversity ..." KI 1.

KI 2 echoed this:

"These are our students, our LGBTI community ... and I don't think management have really addressed that, you know." KI 2.

Yet another key informant (KI 3) concurred:

"I feel that too little is being done. I can't think of a single thing ... management can really do a lot more ..." KI 3.

An explicit policy, according to WHO (2018, n.p.), "defines a vision for the future" and it outlines the priorities and expected roles of all important players. The lack of governance and leadership in the promotion of diversities in sexual orientation and gender identity within the university according to key informants, gives rise to a silencing of these matters in the campus space. KI 2 described it as:

“... it's like a sensitive, not a sensitive topic but it's a topic that people are a bit scared of.” KI 2.

Sexual minority issues are a taboo in the institutional space and according to KI 3, these matters are not regarded as important and is avoided by all cost.

"they never talk about like LGBTI issues like no, that's not the main aim it's like part of diversity. I don't know whether that is because (silence) there is not enough will to only tackle the LGBTI issues or whether it is because ...” KI 3 .

KI 2 agreed:

"So perhaps they calling it diversity, it's like you take away a lot of the negative stuff that diversity should address and it's like a general human rights sort of thing. All minorities are supposed to be represented in this way ...” KI 2.

The narratives highlighted above typify the characteristics of a dominant oppressive system that operates through systematic silencing of sexual minority issues. According to key informants, 
the university celebrates diversity week annually but this is just a public relations exercise so they can show that they have ticked the boxes for transformation. The systematic silencing or avoidance of LGBTI issues demonstrated above show how institutions, through their discourses, policies (or lack of them), and everyday actions reinforce a heteronormative discourse, upholding social structures and attitudes that grant privilege based on heterosexuality. This was again emphasised by KI 3:

"I think in many ways uh there is still that heteronormative vibe on campus but as for the actual LGBTI community I feel almost, on this campus, I don't know about other universities, it feels, again like I said kind of invisible and quite silent. I think there can be more done.” KI 3.

Wickens and Sandlin (2010) agree that HEIs that uphold social structures and attitudes that grant privilege based on heterosexuality reinforce a heteronormative discourse. Almost all key informants were in agreement that the campus environment exerts elements of a heteronormative nature and has an impact on how LGBTI students experience the campus healthcare system. This according to Wickens and Sandlin (2010) is a typical example of heterosexism at play. Homophobia they say, emphasises individual attitudes, behaviours, and beliefs, but heterosexism underscores societal structures and power inequities. Another example that was highlighted by KI 2 also demonstrates how these oppressive systems affect the campus atmosphere and almost certainly police the behaviours of students with nonnormative identities and diverse sexualities.

"Basically, the men the gay men would say to me that they feel like they constantly have to shift their identities. So, when they off campus with a bunch of friends they can be who they want to be. However, they are particularly aware of their sexual identities on campus. So, the way they dress, talk and mannerisms. These are the type of things they keep on managing on campus because in a way they don't want to be seen or labelled as the gay kid". KI 2.

KI 3 empathised with LGBTI students and described how she would feel if she was an LGBTI student:

"As an LGBTI student I would say I will feel like I am in a bottle and this bottle is closed because I don't know whether this is a safe environment for you to be free to everybody and for everyone to know your sexuality. ... So you are in this environment where you can, you are not able to breathe just because of your sexual identity. So I, it's, I think that is how I would feel if I was a student who's belonging to the LGBTI community." KI 3.

The invisibility of LGBTI issues or homosexuality mentioned earlier and the central thesis of the two statements above capture the workings of an ideological system, whose main goal is to 
deny, denigrate, and stigmatise any form of non-heterosexual behaviour, identity, relationship, or community (Wickens and Sandlin 2010). KI 1's statement below captures the collective thoughts of all key informants:

“... I don't think there are a lot of leadership when it comes to LGBTI rights and how we can improve the environment ... management can make their position also bit more clearer what they feel about sexual orientation and gender rights on campus." KI 1.

The picture of the heteronormative campus environment that is painted by key informants has been found to filter through to the campus healthcare system.

\section{Healthcare system-related factors}

The campus healthcare system does not operate in a vacuum; it is very much a part of the larger university system and is, therefore, a reflection of the campus environment, according to key informants.

\section{A heteronormative healthcare system}

The findings show how the dominant heteronormative campus environment is seeping through to the campus healthcare system. The narratives from key informants corroborate their beliefs that this oppressive system is controlling the demand and supply of LGBTI-specific healthcare services. Key informants identified only a few healthcare services targeting LGBTI students specifically and these were mostly in relation to HIV and AIDS awareness, treatment and prevention. The fragmented state of healthcare targeting LGBTI students is a major concern for key informants because it makes these services inaccessible to these students. This is particularly worrisome for new LGBTI students entering the university. KI 3 described some of the healthcare discrepancies present in the campus healthcare system as follows:

"I find that you know (laughing) fragmentation of the system (talking about LGBTI specific services). It's the biggest problem. We are not all having a clear one direction and it makes the programme not sustainable. Currently we don't have a programme. We have events for LGBTI which is a concern because there is no sustainability when you have that type of a strategy". KI 3.

Another key informant KI 1 shared her concern regarding the healthcare disparities:

"With LGBTI we don't have an office like that. Each one of health and wellness departments is doing their own part and it is not coordinated. We make plan, we make means. So, there is no office that's the first thing. So if I am an LGBTI member and I come to the university, I am new, so I won't know where to go when I need support ..." KI 1. 
KI 2 confirmed that most LGBTI students reported that they were unaware of any LGBTIspecific healthcare services on campus:

"Funny enough the ones that came to psychological services, for coming out issues had no idea that there is any gay organisation and services on campus at all." KI 2.

The knowledge gaps about appropriate health services by LGBTI students is indicative of a non-responsive environment that discriminates against LGBTI students.

\section{Heterocentric healthcare services}

The researcher posed the following question to all key informants during the interviews: "Do you think that we need specific healthcare services for LGBTI students?" Only one out of the five key informants felt that healthcare services for LGBTI students were unnecessary. While it is not the purpose of this article to single out the responses from a particular key informant, it is important to highlight significant anomalies that emerged from the data. Almost all key informants mentioned examples of how particular healthcare services for LGBTI students are difficult to access. KI 5 was of the opinion that the:

“... campus healthcare system ... I would say it caters for heterosexuals ... coz you can see even with the staff members. They not trained, they not trained to deal with the LGBTI community coz for them it's shocking to see such people ..." KI 5.

KI 4 differed, saying:

“... with healthcare we treat all patients equally; it's one of the ethical obligations ...” KI 4.

The statement from KI 4 was captivating because it was a direct contradiction to what other key informants were saying. Upon probing for deeper meaning, KI 4 suggested that the biology of sexually-diverse students is the same as those for heterosexual students and, therefore, there is no need for a tailormade programme for LGBTI students. The statement by KI 4 below is also a good example of how heterosexuality is privileged above all other forms of sexuality:

"So when you talk anatomy, anatomy remains anatomy whether you are gay or you are lesbian. You know when you are male or female uh LGBTI it remains the same. You know a penis is a penis, a vagina is a vagina ... So uh I will definitely tell we don't have a specifically tailormade health and wellness programme for the LGBTI. They fit within the current system." KI 4. 
The contradictions in how key informants view targeted healthcare for LGBTI students is important because it highlights the dynamics of heteronormativity in the campus environment and how it affects the worldview of some healthcare providers and potentially the quality of care they deliver. One can also easily identify the healthcare disparities prevalent in the campus healthcare system.

\section{DISCUSSION}

The aim of this article was to explore the perceptions held by key informant interviewees regarding the experiences of LGBTI students in accessing healthcare. This study concluded that structural and systemic barriers to healthcare exert an influence on the demand and supply of targeted healthcare services for LGBTI students on campus. While this study contributes towards important understandings of how historical, oppressive systems in the higher education sector in South Africa are still creating various structural and systemic barriers for LGBTI students to access healthcare, more empirical research is needed to understand the direct impact of these barriers on the health and well-being of sexually diverse students.

\section{Structural and systemic barriers to healthcare}

Structural barriers that operate at the institutional level are embedded in traditional heterosexual social structures, morals, social mores, fundamentalist religious beliefs, and homophobia (Bell et al. 2011), and, according to the key informants, they restrict access to healthcare services for LGBTI students on campus. The slow pace of transformation in the higher education sector in South Africa is responsible for this because, for far too long, the focus has been on race and gender (i.e. male and female), at the expense of other forms of discrimination and therefore these issues remain a taboo in many institutions (Msibi 2013). Sexual minority issues are disguised or couched under the umbrella of diversity, and according to the key informants, this is a clear example of how sexual orientation and gender identity are silenced in the campus environment. The social conditioning that takes place in the campus environment further engrain these institutional practices (Enson 2015). While socially constructed codes and belief systems remain distinct from objective reality, it nonetheless plays a critical role in governing and controlling our lives. In other words, "power" in this context means the ability to influence others to act in a particular way.

I concur with Bell et al. (2011) that, while it is widely accepted that sexual orientation and gender identity are important aspects of diversity, they remain an invisible component in these discussions. Key informants suggest that management should take decisive action by affirming their position to normalise non-heterosexual identities through explicit policies and other 
governance interventions. It has been illustrated how the creation of an open and supportive campus atmosphere towards LGBTI students is facilitated by inclusive and non-discrimination policies in the higher education sector (Messinger 2002). It is critical for management to understand how these dominant oppressive systems operate if any attempt to improve the health and healthcare experience of LGBTI students on campus is to succeed.

The institutional culture perpetuates a heteronormative campus climate. Institutional culture is not always overt and has the potential to systematically exclude certain people from accessing much-needed resources in that system. Institutional culture, according Swindler (1986), constitutes a blending or mixture of organisational culture and the disciplinary institution (this is explained in the next paragraph) as defined by Foucault (1995). Culture is described as a toolkit of habits, skills and styles and is used by people to construct strategies of action. In the context of the university, he (Foucault) reasons, culture encapsulates people's practices, how they negotiate challenges and how they interact and behave. Concerning belief systems within the university, he argues, culture is about the nature of an organisation and what it means to exist within it. Culture does not exist in a vacuum (Wright-Mair 2017); it is part of a larger social context or ecological system, and it is very important, according to Thornton and Ocasio (1999), that one consider carefully patterns of historical assumptions, values, beliefs and rules and how these shape the meaning of the social realities of those within the system.

A heteronormative campus environment restricts the availability of targeted healthcare services for LGBTI students and renders them invisible. Heteronormativity operates similar to Jeremy Bentham's 1791 panopticon (Woolley 2017), which is described by Foucault (1995) as disciplinary power that has the potential to change behaviour. Foucault argues that modern society is a "disciplinary society", meaning that power is largely exercised through disciplinary means. Heteronormativity just like panopticism is a system that regulates and surveys the behaviour of LGBTI students. Behaviour that is deemed inconsistent with heteronormative norms is regarded as deviant and deserving of punishment. Under the circumstance, LGBTI students are forced to keep their sexual orientation private and, according to key informants, they constantly have to manage their behaviour in fear of not being "outed" by heterosexual students.

\section{Campus healthcare system factors}

A combination of factors including a lack of political will and a silencing of sexual minority issues were identified by key informants as influencing the demand and supply of targeted healthcare services for LGBTI students on campus. The supply-side determinants of LGBTI healthcare or those factors inherent in the healthcare system do not escape the larger 
heteronormative campus climate since it shares the same geographical space and is subjected to the same political and cultural norms and values. Reportedly, the healthcare services offered on campus, mainly focus on heterosexual students which Mavhandu-Mudzusi (2016, 3) describes as "heterocentric in nature", meaning that they discriminate against non-heterosexual students.

As a result of the slow pace of transformation in the higher education sector in South Africa which has tended to focus on race and gender, at the expense of other forms of discrimination (Msibi 2013), issues of sexual orientation and gender identity remain taboo. The findings of this study showed that LGBTI students are underserved in the campus healthcare system and that this is the result of dominant oppressive structures and mechanisms in the campus environment that uphold and maintain the order of normalising heterosexuality, thereby rendering sexual minority students invisible. In turn, this impacts the demand and supply for LGBTI-specific healthcare on campus. This, according to the key informants, means that if LGBTI students are rendered invisible on campus, then there is no need to plan for this group of students.

The ideology behind invisibility in healthcare and what has been used as justification to discriminate against non-heterosexual people for many years, surfaced in the narratives of one key informant whose views were in total contrast to the other four key informants. The astonishing thing about this is how the systematic erasure of LGBTI matters are justified by ethical obligations in healthcare (e.g. "it's my ethical obligation to treat everyone equally in healthcare") and yet it is a human rights violation to deny any person culturally-appropriate healthcare services (Sections 27 (1) (a), (b) and(c); Section 28 (1) (c) and Section 35 (2) (e) of the Constitution of the Republic of South Africa, Act 108 of 1996). It is imperative for healthcare providers according to Lagro-Janssen $(2010,1)$ to "expand their awareness of how gender shapes individual behaviour, thought and prejudice" in order to provide healthcare services that meet the needs of individuals. Another observation of note is how the worldview of the healthcare provider can influence the quality of services rendered. Healthcare providers, according to Mavhandu-Mudzusi (2016), whose worldview is based on cultural beliefs and practices, are likely to display discriminatory attitudes towards LGBTI individuals.

\section{Wider implications}

The findings of this study are important to aiding our understanding regarding the experience of LGBTI students when they access healthcare on campus. The study is a qualitative study and therefore the data cannot be generalised to the entire student population and data collected from five key informants in no way supports a representative view of all important role players in 
the campus environment. However, the data raises important issues for university management to consider in order to improve the experience of LGBTI students in accessing healthcare on campus. Another significant limitation of the study is that, during the time of the study, the researcher was employed at the university where the study was conducted and worked very closely with many student organisations. This might have potentially biased the selection of the key informants and possibly the interpretation of data. As a gender, non-conforming and sexually-diverse member of the LGBTI communities himself, the researcher is cognisant of the fact that his personal involvement in the research topic might have influenced his interpretation of the data. However, the researcher regularly consulted with the study supervisor for regular check-in, and periodic reflexive exercises also kept him grounded to focus on the objectives of the study. It is important that these findings are read and interpreted, considering these limitations.

There is a strong need for transformation in the higher education sector in South Africa and HEIs, in particular, need to make issues of sexual orientation and gender identity a central agenda item in their transformation policies.

HEIs, especially those with Health Sciences faculties, need to consider options on how to integrate aspects of sexual orientation and gender identity into the mainstream curriculum in order to improve the cultural competencies of healthcare providers. Culturally-competent healthcare service providers are especially important among sexual and gender minority students because poor cultural competence contributes to health disparities and this will ultimately affect academic performance. There is a need to understand how to improve healthcare quality and delivery for LGBTI students in particular, because they have unique physical and mental health needs as both LGBTI individuals and students.

\section{CONCLUSION}

Four out of the five key informants that participated in the study portrait the campus as hostile towards LGBTI students. "So you are in this environment where you can ... you are not able to breathe just because of your sexual identity" KI 2. This quotation sums up the perceptions held by key informants. The findings concur with the recommendation made by Arndt and De Bruin (2006) almost a decade ago on the importance of examining the higher education sector as a whole, and that HEIs, in particular, be assessed on a continual basis on whether transformation policies are effectively addressing issues of sexual orientation and gender identity. It is shocking to note that more than 10 years later, we are still dealing with the same issues. These are remnants of our oppressive past and a prime indication of how sluggishly the pace of transformation is unfolding in the higher education sector, one of the sectors that society 
entrusted with the responsibility to enlighten the nation on these and other important political and social issues.

\section{REFERENCES}

Arndt, Marlene and Gideon de Bruin. 2006. Attitudes toward lesbians and gay Men: Relations with gender, race and religion among university students. Psychology in Society 33: 16-30.

Badat, Saleem. 2009. Theorising institutional change: Post-1994 South African higher education. Studies in Higher Education 34(4): 455-467.

Bell, Myrtle P., Mustafa F. Özbilgin, T. Alexandra Beauregard and Olca Sürgevil. 2011. Voice, silence, and diversity in 21st Century organizations: Strategies for inclusion of gay, lesbian, bisexual, and transgender employees. Human Resource Management 50(1): 131-146.

Binson, Diane, Johnny Blair, David M. Huebner and William J. Woods. 2007. Sampling in surveys of lesbian, gay, and bisexual people. In The health of sexual minorities, 375-418. Boston: Springer.

Brink, Jaco, G. 2017. Considerations for South African higher education: A "National student men who have sex with men" Sexual Behaviour Survey. South African Journal of Higher Education 31(4): 184-207.

Bunting, Ian. 2006. The higher education landscape under apartheid. In Transformation in higher education. Higher education dynamics, ed. Nico Cloete, Peter Maassen, Richard Fehnel, Teboho Moja, Helene Perold and Trish Gibbon, Chapter 2: 35-52.10: 227-244. Dordrecht: Springer.

Constitution of the Republic of South Africa. 1996. Act 108 of 1996. Government Gazette (No. 17678).

Creswell, John, W. 2007. Qualitative inquiry and research design: Choosing among five traditions. $2^{\text {nd }}$ Edition. Thousand Oaks: Sage.

Creswell, John, W. 2014. Research design: Qualitative, quantitative and mixed methods approaches. $4^{\text {th }}$ Edition. Thousand Oaks: Sage.

Creswell, J. W. and D. L. Miller. 2000. Determining validity in qualitative inquiry. Theory into Practice 39(3): 134-130.

Enson, Stephanie. 2015. Causes and consequences of heteronormativity in healthcare and education. British Journal of School Nursing 10(2): 73-78.

Ensor, Tim and Stephanie Cooper. 2004. Overcoming barriers to health service access: Influencing the demand side. Health Policy and Planning 19(2): 69-79.

Foucault, Paul-Michel. 1995. Discipline and punish: The birth of the prison. (Translated from the French by Alan Sheridan). New York: Vintage Books (Original Work Published in 1975).

Francis, Dennis A. 2017a. "I think we had one or two of those, but they weren't really": Teacher and learner talk on bisexuality in South African schools. Journal of Bisexuality 17(2): 206-224.

Francis, Dennis A. 2017b. Homophobia and sexuality diversity in South African schools: A Review. Journal of LGBT Youth 14(4): 359-379.

Francis, Dennis. 2018. "Keeping it straight": What do South African queer youth say they need from sexuality education? Journal of Youth Studies (2018): 1-19.

Francis, Dennis and Thabo Msibi. 2011. Teaching about heterosexism: Challenging homophobia in South Africa. Journal of LGBT Youth 8(2): 157-173.

Haas, Ann P., Mickey Eliason, Vickie M. Mays, Robin M. Mathy, Susan D. Cochran, Anthony R. D'Augelli, Morton M. Silverman et al. 2010. Suicide and suicide risk in lesbian, gay, bisexual, and transgender populations: Review and recommendations. Journal of Homosexuality 58(1): 10 51.

Hatzenbuehler, Mark L. 2011. The social environment and suicide attempts in lesbian, gay, and bisexual youth. Pediatrics 127(5): 896.

Institute of Medicine (US) Committee on Lesbian, Gay, Bisexual, and Transgender Health Issues and 
Research Gaps and Opportunities. 2011. The health of lesbian, gay, bisexual, and transgender people: Building a foundation for better understanding. Washington: National Academies Press.

IOM see Institute of Medicine.

Jacobs, Bart, Por Ir, Maryam Bigdeli, Peter Leslie Annear and Wim Van Damme. 2012. Addressing access barriers to health services: An analytical framework for selecting appropriate interventions in low-income Asian countries. Health Policy and Planning 27(4): 288-300.

Jooste, Karien, Jose Frantz and Firdouza Waggie. 2018. Challenges of academic healthcare leaders in a higher education context in South Africa. Educational Management Administration \& Leadership 46(4): 692-708.

Lagro-Janssen, Toine. 2010. Gender and sex: Issues in medical education. Tijdschrift voor Medisch Onderwijs 29(1): 48-53.

Matthyse, Glenton. 2017. Heteronormative higher education: Challenging this status quo through LGBTIQ awareness-raising. South African Journal of Higher Education 31(4): 112-126.

Mavhandu-Mudzusi, Azwihangwisi H. 2016. Citizenship rights, discrimination and stigmatisation of LGBTI students by health care services at a South African rural-based university. Agenda 30(1): $104-111$.

Messinger, Lori. 2002. Policy and practice: A holistic approach to addressing homophobia and heterosexism among social work students. Journal of Lesbian Studies 6(3-4): 121-132.

Msibi, Thabo. 2013. Queering transformation in higher education. Perspectives in Education 31(2): 6573.

Müller, Alex. 2017. Scrambling for access: Availability, accessibility, acceptability and quality of healthcare for lesbian, gay, bisexual and transgender people in South Africa. BMC International Health and Human Rights 17(1): 16.

Nduna, Mandisa, Amukelani Mthombeni, Azwihangwisi, H. Mavhandu-Mudzusi and Immaculate Mogotsi. 2017. Studying sexuality: LGBTI experiences in institutions of higher education in Southern Africa. South African Journal of Higher Education 31(4): 1-13.

O'Donnell, Owen. 2007. Access to health care in developing countries: Breaking down demand side barriers. Cadernos de Saude Publica 23: 2820-2834.

Peters, David H., Anu Garg, Gerry Bloom, Damian G. Walker, William R. Brieger and M. Hafizur Rahman. 2008. Poverty and access to health care in developing countries. Annals of the New York Academy of Sciences 1136(1): 161-171.

Ritchie, Jane, Liz Spencer, and William O'Connor. 2003. Carrying out qualitative analysis. In Qualitative research practice: A guide for social scientist students and researchers: ed. Jane Ritchie and Jane Lewis, 219-262. London: Sage.

Rothmann, Jacques. 2018. A social constructionist approach to resilience for lesbian, gay, bisexual, transgender, intersex, queer and/or questioning academics and students in South African universities. Transformation in Higher Education 3(3): 1-8.

Soudien, Crain. 2008. The intersection of race and class in the South African university: Student experiences. South African Journal of Higher Education 22(3): 662-678.

Strutz, Kelly L., Amy H. Herring and Carolyn Tucker Halpern. 2015. Health disparities among young adult sexual minorities in the US. American Journal of Preventive Medicine 48(1): 76-88.

Thornton, Patricia H. and William Ocasio. 1999. Institutional logics and the historical contingency of power in organizations: Executive succession in the higher education publishing industry, 19581990. American Journal of Sociology 105(3): 801-843.

Swindler, Ann. 1986. Culture in action: Symbols and strategies. American Sociological Review 51(2): 273-286.

WHO see World Health Organization.

Wickens, Corrine M. and Jennifer A. Sandlin. 2010. Homophobia and heterosexism in a College of Education: A culture of fear, a culture of silence. International Journal of Qualitative Studies in 
Education 23(6): 651-670.

Woolley, Susan W. 2017. Contesting silence, claiming space: Gender and sexuality in the Neo-Liberal Public High School. Gender and Education 29: 84-99

World Health Organization. 2011. 64th World Health Assembly. Resolution WHA 64.28: Youth and Health Risks. Geneva. http://apps.who.int/gb/ebwha/pdf_files/wha64/a64_r28-en.pdf (Accessed 25 April 2019).

World Health Organization. 2018. Health Policy. http://www.who.int/topics/health_policy/en/ (Accessed 25 April 2019).

Wright-Mair, Raquel. 2017. A phenomenological exploration of how campus environments shape the success of racially minoritized faculty at predominantly white institutions. $\mathrm{PhD}$. Thesis. University of Denver. 